\title{
A comprehensive review of in situ polymer hydrogels for conformance control of oil reservoirs
}

\author{
Kelly Lúcia Nazareth Pinho de Aguiar ${ }^{1, *}$, Priscila Frias de Oliveira ${ }^{1}$, and Claudia Regina Elias Mansur ${ }^{1,2}$ \\ ${ }^{1}$ Federal University of Rio de Janeiro, Institute of Macromolecules, Horácio Macedo Avenue, 2030-Block J, \\ 21941-598 Rio de Janeiro, Brazil \\ ${ }^{2}$ Federal University of Rio de Janeiro, Program of Materials and Metallurgy Engineering/COPPE, \\ Horácio Macedo Avenue, 2030-Block F, 21941-598 Rio de Janeiro, Brazil
}

Received: 9 October 2019 / Accepted: 11 December 2019

\begin{abstract}
In fractured reservoirs, fluids injected Enhanced Oil Recovery (EOR) are channeled through the fracture zones and travel through highly permeable regions, failing to displace part of the oil, and decreasing oil recovery efficiency. To solve these problems, the conformance control technique is now widely used, as it allows the reservoir to be swept totally, similar to the ideal condition. In this context, polyacrylamide-based polymer gel systems can be used to block the high-permeability regions of the rock matrix, forming in situ hydrogels that block the rock pores, avoiding the channeling of the fluids, and increasing the oil production. These polyacrylamide-based hydrogels can be crosslinked by inorganic (metal ions) or organic substances, and various systems are used for conformance control. Due to the greater stability of the bond formed between the polymer and the organic crosslinker, these systems are now used in higher temperature reservoirs. In order to produce hydrogels with higher resistance to severe salinity and temperature conditions, nanoparticles are applied to form systems with good mechanical resistance, and high thermal stability. These have presented promising results for conformance control.
\end{abstract}

\section{Introduction}

Oil production is crucial for the global economy and its demand tends to increase by $1.5 \%$ per year (El-Hoshoudy et al., 2017). There are a variety of technologies to facilitate the extension of the field life, such as advanced reservoir characterization, artificial lift optimization, conformance control, and various enhanced recovery schemes (Ali, 2010). Conformance control is any process by which the sweeping of a reservoir is spread more evenly, approaching the ideal condition of a perfectly conforming drive mechanism, minimizing water production (Bai et al., 2015a).

In fractured reservoirs, injected fluids have a strong tendency to traverse regions of higher permeability, failing to displace some of the oil that could otherwise be recovered, thereby decreasing sweep efficiency (Chung et al., 2011; Sheng, 2010). Another problem that occurs in mature fields is the large amount of produced water, which results in higher costs for oil separation processes, equipment corrosion, premature well abandonment, and environmental concerns related to the disposal of this water, among others (Al-Muntasheri, 2012; Imqam and Bai, 2015).

* Corresponding author: kellypinho@ima.ufrj.br
There are several types of water control treatments. The standouts are conventional zone-blocking water shut-off treatment and Relative Permeability Modifier Treatment (RPMT) (Alfarge et al., 2018). The first treatment involves blocking the entire flow in a completely water-producing zone or stratum of the reservoir. The water shut-off material is normally a strongly crosslinked polymer gel, often referred to as a "blocking gel" (Cai and Huang, 2001). The second treatment includes selectively reducing the water while allowing the oil to flow freely or with minimal reduction. The material used in this operation is normally a polymer with low level of crosslinking (Al-Nakhli et al., 2013).

Polymer hydrogels can be used as blocking gels, changing rock characteristics, and displacement mechanism, improving sweep efficiency, and consequently leading to a higher oil recovery rate (Lakatos and Lakatos-Szabó, 2008). These systems are injected in the reservoir formation from an injection well or a producing well, typically with 5-15 ft. (1.5-4.5 m) radial penetration (Powell et al., 2004). The goal is to make the gel flow to the most permeable zones, sealing them by forming an impermeable blockage of the pores of the fractured rock. Through this process, water production can be decreased and oil production increased (Al-Muntasheri, 2012; Goudarzi et al., 2015; Liu et al., 2010). The polymer gel systems used for this type 
of treatment are usually composed of a polymer and inorganic or organic crosslinking agent, and are divided into two categories: in situ gels and Preformed Particle Gels (PPGs) (Lenji et al., 2018). In this method, in situ gels are injected into the reservoir to form a 3D gel network structure, under reservoir conditions (temperature, salinity, and $\mathrm{pH}$ ) so as to efficiently block water currents and reduce permeability (Seright, 1991; Sydansk and Moore, 1992). PPGs, however, undergo crosslinking before injection into the reservoir, forming gel under surface conditions, and being injected as preformed particles. In situ gel systems are less expensive, so they are the most widely used for conformance control (Goudarzi et al., 2015; Imqam and Bai, 2015). The focus of this literature survey is the use of polymer hydrogels for water control treatment of oil reservoirs as "blocking gels" for in situ application.

\section{Polymer gel systems for conformance control}

In order to remedy conformance problems in reservoirs with high heterogeneity, characterized by fractured regions, and higher permeability zones, polymer gel systems can be used because of their easy pumping, low cost and ability to penetrate and change the reservoir permeability profile, leading to higher oil production (El-Karsani et al., 2014a; Ma et al., 2017; Tongwa and Baojun, 2015).

These systems are composed of a water-soluble polymer and crosslinking agent and were initially developed for in situ hydrogel formation (El-Karsani et al., 2014a). When injected, the gelling process occurs inside the pores of the reservoir rock, generating a three-dimensional structure called hydrogel. The hydrogel acts as an impermeable physical barrier to water flow. By sealing the areas of greatest permeability, the injected fluids are forced to move to regions of low permeability, zones with large amounts of non-swept oil. This increases oil recovery (El-Karsani et al., 2014a; Tongwa and Baojun, 2015; Zhu et al., 2017a). This mechanism of blocking and changing the reservoir permeability profile is depicted in Figure 1.

The hydrogels have viscoelastic properties and their three-dimensional structure is formed by crosslinks that can involve van der Waals interactions, physical interlacing, ionic complexation, covalent bonding or hydrogen bonding, depending on the type of polymer, and the crosslinking agent used (Shibayama and Tanaka, 1993). Thus, the hydrogel does not dissolve in the porous medium and the transition time of the injected solution to the hydrogel (the three-dimensional structure formed), as well as its viscoelastic properties, strongly depend on the conditions of the petroleum reservoir, and the concentrations of the system's components (El-Karsani et al., 2014b; Yavari-Gohar et al., 2010; Zhu et al., 2017a).

Oil reservoir conditions such as temperature, salinity, hardness, and $\mathrm{pH}$ of the formation water, rock fracturing pressure, permeability of the target zone, and the lithology of reservoir formation are important for the development of hydrogels (Manrique et al., 2012; Zhu et al., 2018). According to Tessarolli et al. (2014), polymer hydrogels need to

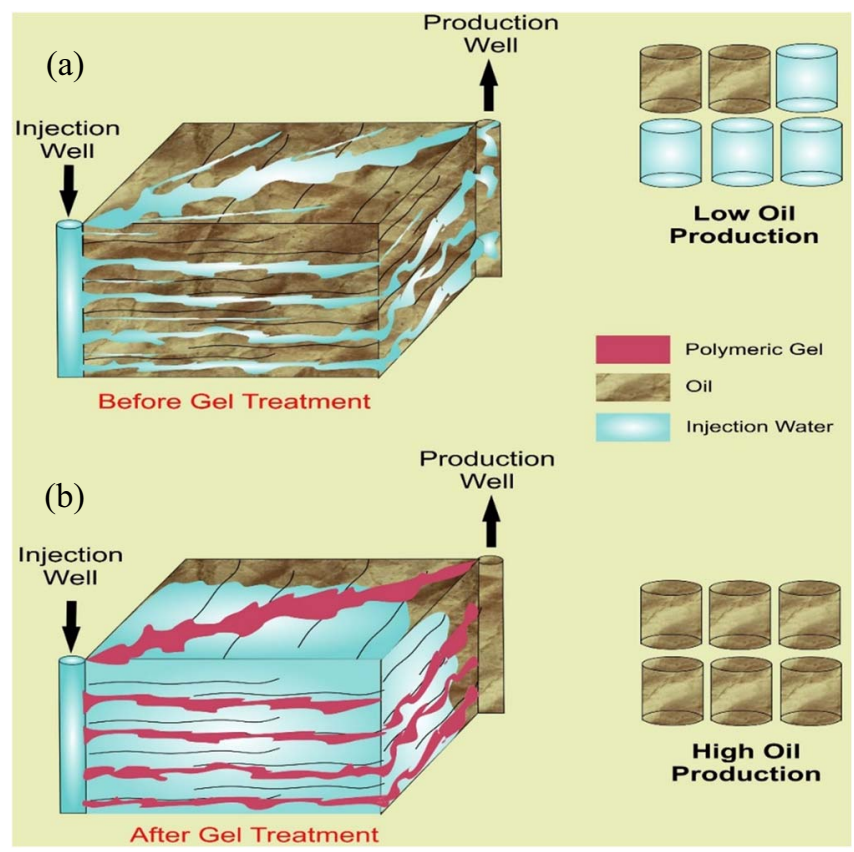

Fig. 1. Mechanism of action of the blocking gels, where: (a) the injected fluid flows preferentially through zones of greater permeability, reducing oil production and (b) formation of polymer gel preferentially in the thief zones of the reservoir, displacing the injected water to regions with lower permeability and increasing oil production.

have: (i) good injectivity (adequate intrinsic viscosity); (ii) low adsorption of their components in the porous medium and good propagation; and (iii) programmable gelation time.

To verify the applicability of hydrogel in conformance control, it is important to evaluate the gelling behaviors, such as:

(a) Gelation time - determines the length of time and depth that the system will reach when forming the impermeable barrier in the rock-reservoir.

(b) Gel strength and stability - indicate the performance of the hydrogel as a blocking agent.

These behaviors strongly depend on the type of polymer (molecular weight and degree of hydrolysis), polymer and crosslinking concentration and crosslinking agent type.

In general, polymer hydrogels should have a minimum gelation time of $2 \mathrm{~h}$ to ensure that the gel does not form during fluid injection. However, when the system is applied in regions far from the destination site, the minimum time passes to weeks or even months. The hydrogel formed must have thermal and chemical stability to withstand, under tank conditions, a minimum aging time of 6 months (Bai et al., 2015b; Dang et al., 2014; Johnson et al., 2010; Zhang et al., 2017).

Several in situ gel systems are being developed for the oil industry, such as gels based on synthetic polymers and 
PAM

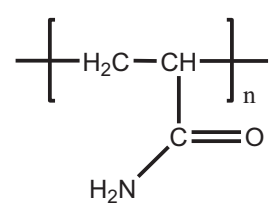

PHPA

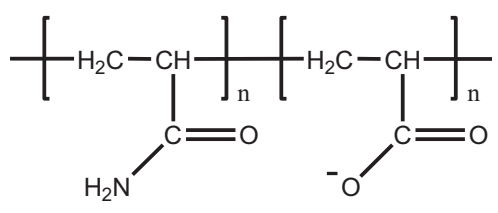

Fig. 2. Structure of polymers: (a) Polyacrylamide (PAM) and (b) Partially Hydrolyzed Polyacrylamide (PHPA).

polysaccharides (biopolymers) like xanthan gum, cellulose, starch, and lignin, among others (Bai et al., 2015a). However, the costs to obtain the raw material and process biopolymers are very high, which often makes their use unfeasible. Thus, the use of synthetic polymers stands out, and the most prevalent are Polyacrylamide (PAM)based gels (Bai et al., 2015a; Jia et al., 2012).

Polyacrylamide (Fig. 2a) is a water-soluble and electrically neutral polymer formed by a carbon chain with suspended amide groups. When exposed to high temperature or a small amount of alkaline solution, it undergoes thermal or basic hydrolysis, respectively, where amide groups are converted into anionic carboxylates groups, generating Partially Hydrolyzed Polyacrylamide (PHPA) (Fig. 2b). Thus, it forms a copolymer of acrylamide and acrylic acid (Ma et al., 2015; Tongwa et al., 2012).

The chemical properties and the ability to form viscous systems depend mainly on the molecular weight, degree of hydrolysis, and chemical composition of the polymer. For the preparation of gel systems, polyacrylamide has a high molecular weight, and in most cases a hydrolysis degree between $10 \%$ and $35 \%$ (Wever et al., 2011). With the increase in the hydrolysis degree, the main chain of the polymer presents stronger electrostatic charges, which generate elongation of the polymeric chain in water due to electric repulsion, causing an increase in the viscosity of the system. However, a very high degree of hydrolysis can cause greater sensitivity to the salinity of the medium (Wever et al., 2011).

Polyacrylamide hydrogels are sensitive to divalent ions and temperature. In brines with high concentrations of divalent cations, such as $\mathrm{Mg}^{2+}$ and $\mathrm{Ca}^{2+}$, these cations interact with PHPA carboxylate anions, resulting in polymer precipitation. Thus, the possibility of precipitation with divalent ions increases with the use of polyacrylamide with a higher degree of hydrolysis (Reichenbach-Klinke et al., 2011; Thomas et al., 2012).

According to Ma et al. (2015), gels produced with polyacrylamide can be used for the treatment of reservoirs with temperatures below $90{ }^{\circ} \mathrm{C}$. At higher temperatures, the thermal hydrolysis of the amide polyacrylamide groups accelerates, causing gel syneresis, which consists of the shrinking of the gel volume, and consequent expulsion of the water from the structure due to the increased density of crosslinks (Guan et al., 2014).

Aiming to improve the thermal stability and salinity resistance of these gels, some polymers have been developed from the copolymerization of PAM with comonomers, such as Vinylpyrrolidone (VP), 2-Acrylamid-Methylpropane

Sulfonic (AMPS) acid or its Sodium 2-Acrylamid-Methylpropane Sulfonate (Na-AMPS) salt, and Tert-Butyl Acrylate (tBA) (El-Karsani et al., 2014a; Thomas et al., 2012; Zhang et al., 2017).

In general, these groups in PAM's polymeric chain exert a shielding effect, protecting the amide groups from thermal hydrolysis, reducing their conversion into carboxylic group, and thus increasing the thermal stability of the polymer. In addition, this makes it more resistant to salinity, because the number of carboxylate anions in the polymer structure decreases, making the interaction of these anions with divalent cations less pronounced (Thomas et al., 2012; Zhang et al., 2017; Zhu et al., 2017a).

Polymer gel systems based on polyacrylamide can be formed from the use of organic crosslinking systems, where their formation occurs by covalent bonds, or inorganic crosslinking systems, crosslinked by ionic bonds (Jia et al., 2012). The following sections address the main types of crosslinking agents used for the formation of gel systems applied for conformance control.

\subsection{Acrylamide-based polymers with inorganic crosslinking systems}

The most widely used inorganic crosslinkers are multivalent metal ions such as $\mathrm{Cr}^{3+}, \mathrm{Al}^{3+}, \mathrm{Zr}^{4+}, \mathrm{Fe}^{3+}$, and $\mathrm{Ti}^{3+}$ to form gel systems with polyacrylamide-based polymers. The polyacrylamides used for in situ gel systems are all partially hydrolyzed to carry a negative charge. The crosslinking mechanism of these gels is the ionic bond between the negative charges of the polymer carboxylate groups and the multivalent cations (Jia et al., 2010; Zhu et al., 2017b).

These metal ions can be found in the form of soluble chemical complexes in solution or as simple inorganic ions. The rate and extent of the reaction depends heavily on the binder structure of the crosslinking agent. $\mathrm{Cr}$ (III) is the most used metallic ion for the formation of these systems, but its oxidation can generate $\mathrm{Cr}(\mathrm{VI})$, which is highly carcinogenic and thus has a great disadvantage in relation to other inorganic crosslinkers (Albonico et al., 1993; Jia et al., 2012; Vargas-Vasquez and Romero-Zerón, 2008).

The first polymer gel system formed for conformance control was produced by Routson and Caldwell (1972) from PHPA injection with a diluted $\mathrm{Cr}$ (III) hydroxide solution. However, a lack of control of the gelation time was observed. In the early 1980s (American Petroleum Institute, 1982), a study was performed of PHPA crosslinked with aluminum sulfate and a close relationship was observed between these systems and the $\mathrm{pH}$ conditions, because when the polymer was mixed with aluminum sulfate under acid conditions in surface installations, the mixture did not form a gel immediately and could be successfully injected into the reservoir, but when the fluids penetrated the formation, the $\mathrm{pH}$ increased very fast, causing gelling to occur in an uncontrolled manner, making its application impossible in areas far from the injection well.

In order to improve the gelation time and ensure the formation of the gel in the desired region, several authors have conducted studies using multivalent ions in the form of complexes, such as citrate, acetate, malonate, propionate, 
tartrate, and metallic ion glycolate (Albonico et al., 1993; Bai et al., 2015a; Ghazalli and Willhite, 1985; Kedir et al., 2014; Moradi-Araghi et al., 1988; Needham et al., 1974; Romero-Zerón et al., 2008).

Needham et al. (1974), Ghazalli and Willhite (1985), and Moradi-Araghi et al. (1988) all carried out studies of gel systems with $\mathrm{PHPA} / \mathrm{Al}(\mathrm{III})$ citrate. The authors observed that the citrate ions acted as a protector of the $\mathrm{Al}^{3+}$ ions, allowing the system to be injected into the reservoir with the polymeric solution and to perform crosslinking. Without forming a complex with citrate, aluminum could be hydrolyzed to an aluminum hydroxide precipitate, making the metal ions unavailable for crosslinking, thus not forming gels. In addition, it was found that the $\mathrm{pH}$ range between 6 and 7 is ideal for the gelling of these systems.

Systems based on PHPA/Cr(III) propionate were studied and patented by Mumallah and Shioyama (1987), found to be effective for the treatment of zones with higher permeability near or far from the injection well and resistant to environments with higher salinity.

Sydansk (1988) established and patented a new polymer gel system based on PHPA/Cr(III) acetate. This system achieved great prominence in oil fields. The acetate group has a very similar structure to the carboxylate group present in PHPA. Thus, the $\mathrm{Cr}^{3+}$ ions are attracted both by the negative charges of the PHPA carboxylate group and the acetate binder, delaying the formation of crosslinks and making the gelation time programmable. In addition, these systems had as advantages their resistance to reservoirs with high temperatures $\left(124^{\circ} \mathrm{C}\right.$ or higher) and insensitivity in the $\mathrm{pH}$ range between 2 and 12.5. As a disadvantage, these systems still had low gelation time, precluding their application in areas with greater distance from the injection wells (Sydansk, 1988).

Since then, these $\mathrm{Cr}$ (III) systems have been applied, for example, in the Big Horn Basin in Wyoming, where an increase of 1200000 barrels of oil from stock tanks was observed due to the injection treatment with PHPA/Cr (III) acetate in the wells from 1989 to 1992 (Southwell and Posey, 1994).

Fletcher et al. (1992) studied the ability of systems formed by $\mathrm{PHPA} / \mathrm{Al}(\mathrm{III})$ citrate to withstand environments with formation water having high salt content (30 000 TDS).

Albonico et al. (1993) evaluated the delaying effect of $\mathrm{Cr}$ (III) complexes with glycolate, malonate, and salicylate on PAM-AMPS copolymers at $120{ }^{\circ} \mathrm{C}$. A positive effect was observed, where the gelation time was 12-33 times longer than that gelation time using acetate. It was also found that the delay in gelling is highly dependent on the concentration of the ligand present in the solution and has a direct relationship, which can be explained by the competition of the $\mathrm{Cr}^{3+}$ ions for crosslinking in interacting with the ligand of the complex (Albonico et al., 1993).

Stavland and Jonsbraten (1996) conducted studies of the gelation time with $\mathrm{Al}(\mathrm{III})$ citrate crosslinker at $90{ }^{\circ} \mathrm{C}$ and found that the gelation time varied between 3 and 30 days, with a tendency to increase at higher $\mathrm{pH}$ values and decrease with higher aluminum concentration.
Cai and Huang (2001) evaluated systems with $400 \mathrm{mg} \mathrm{L}^{-1}$ PHPA and different concentrations of Ti(IV) tartrate crosslinker at $50{ }^{\circ} \mathrm{C}$. The authors observed that up to $250 \mathrm{mg} \mathrm{L}^{-1}$ of the crosslinker, the gelation time was effective but above this concentration a polynuclear titanium complex formed, causing less efficient crosslinking, and reducing the gel strength. They also found that the rate of gelling increased with the highest content of sodium chloride in the formation water and that the $\mathrm{pH}$ range for this was between 4.9 and 6.6. Thus, Ti(IV) tartrate can be applied in reservoirs with high salinity, $\mathrm{pH}$ values close to neutral and moderate temperatures.

Grattoni et al. (2001), Seright et al. (2003), Cheng et al. (2005), Vargas-Vasquez and Romero-Zerón (2008), and Romero-Zerón et al. (2008) conducted studies with gel systems of PHPA/Cr(III) acetate. Although the PHPA/Cr (III) acetate gel system has been successful in oil fields, some inherent problems have occurred. Pre-gel aggregates were formed even before a gel network was established. Rock reservoirs filtered them out and retained them according to their size or molecular weight, causing problems in conformance control treatment. Thus, it became necessary to carry out further studies to optimize this process using the components of this system.

Koohi et al. (2010) prepared hydrogels with $\mathrm{Cr}$ (III) acetate and AM-AMPS copolymer. The minimum concentration of polymer to form a gel at $90{ }^{\circ} \mathrm{C}$ was $5500 \mathrm{ppm}$ (0.55\% mass). Parameters such as gelling rate, viscosity and gel strength increased with the use of higher polymer concentrations and crosslinking/polymer ratios, due to the greater availability of carboxylate clusters to interact with $\mathrm{Cr}^{3+}$.

Dang et al. (2014) conducted studies with PHPA having low molecular weight (Alcoflood 254S) at a concentration of $20000 \mathrm{mg} \mathrm{L}^{-1}$ and $\mathrm{Cr}(\mathrm{III})$ acetate, with a crosslinking/ polymer ratio $(R)$ equal to $1 / 40$, and analyzed the influence of temperature on gelation time. Gelation times of $24 \mathrm{~h}$ were observed at $40{ }^{\circ} \mathrm{C}, 4.5 \mathrm{~h}$ at $55^{\circ} \mathrm{C}$, and much shorter times at temperatures of $60-75{ }^{\circ} \mathrm{C}$. In other words, higher temperatures increased the viscosity of the systems, indicating faster gelling. In addition, they studied the gelling behavior in relation to the molecular weight of the polymer used, comparing Alcoflood 254S and PHPA of average molecular weight, commercially known as Alcoflood 955. The influence of molecular weight, where the higher mass polymer formed gel more quickly, was attributed to the higher number of carboxylate clusters to react with $\mathrm{Cr}^{3+}$.

Kedir et al. (2014) developed hydrogels formed of $600 \mathrm{mg} \mathrm{L}{ }^{-1}$ of PHPA with hydrolysis degree of $25-30 \%$ and $20 \mathrm{mg} \mathrm{L}^{-1}$ of $\mathrm{Al}(\mathrm{III})$ citrate (AlCit) and studied the influence of $\mathrm{pH}$ on crosslinking of the systems. They found that these systems were strongly affected by $\mathrm{pH}$ variations, that AlCit was more reactive at almost neutral $\mathrm{pH}$ and therefore crosslinking reactions should preferably be performed under these conditions.

Moghagam et al. (2014) formed systems with PA-AMPS with $25 \%$ sulfonation, known commercially as AN125, using chromium triacetate as crosslinking agent, sodium lactate as retardant, Sodium Montmorillonite (Na-MMT), and brine (sodium chloride $-\mathrm{NaCl}$, calcium 

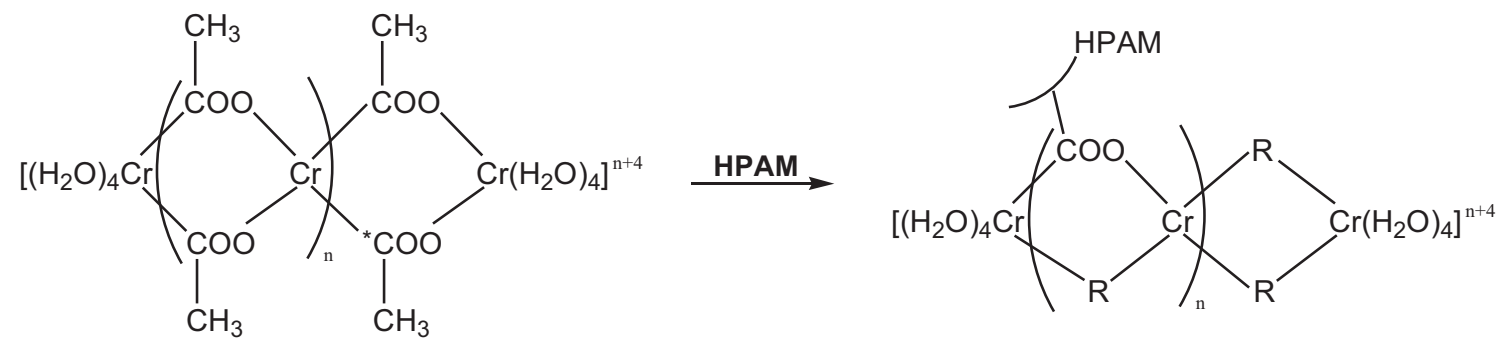

Fig. 3. PHPA/Cr(III) acetate crosslinking mechanism.

chloride $-\mathrm{CaCl}_{2}$, potassium chloride $-\mathrm{KCl}$ and magnesium chloride $-\mathrm{MgCl}_{2}$ ) and carried out a two-level factorial experiment design (multivariate statistical analysis) to find the parameter that most influenced the gelation time of these systems.

The factors evaluated in this design were: $\mathrm{NaCl}$ concentration $\left(15000 \mathrm{mg} \mathrm{L}^{-1}\right.$ or $\left.0 \mathrm{mg} \mathrm{L}^{-1}\right), \mathrm{CaCl}_{2}\left(15000 \mathrm{mg} \mathrm{L}^{-1}\right.$ or $\left.0 \mathrm{mg} \mathrm{L}^{-1}\right), \mathrm{KCl}\left(15000 \mathrm{mg} \mathrm{L}^{-1}\right.$ or $\left.0 \mathrm{mg} \mathrm{L}^{-1}\right)$, and $\mathrm{MgCl}_{2}$ $\left(15000 \mathrm{mg} \mathrm{L}^{-1}\right.$ or $\left.0 \mathrm{mg} \mathrm{L}^{-1}\right)$, temperature $\left(90^{\circ} \mathrm{C}\right.$ or $\left.60^{\circ} \mathrm{C}\right)$, $\mathrm{pH}$ (11 or 3$)$, addition of sodium lactate $(1 \% \mathrm{~m} / \mathrm{m}$ or 0$)$, and Na-MMT $(1 \% \mathrm{~m} / \mathrm{m}$ or 0$)$. Gelation time increased with the use of a retardant and addition of $\mathrm{MgCl}_{2}$, while it decreased with the increase in temperature, $\mathrm{pH}$, addition of Na-MMT and other salts. Temperature had the greatest effect on the gelation time of these systems (Moghagam et al., 2014).

Zhang et al. (2015a) studied the crosslinking mechanism between PHPA and $\mathrm{Cr}$ (III) acetate and observed that the process occurs in two types of reactions. The first reaction consists of intramolecular crosslinking, where $\mathrm{Cr}^{3+}$ interacts with carboxylate groups of a molecule of PHPA; and the second reaction consists of intermolecular crosslinking, where $\mathrm{Cr}^{3+}$ ions interact with carboxylate groups of different molecules of PHPA, generating the three-dimensional structure of the gel and causing an increase in system viscosity.

Figure 3 shows schematically the crosslinking mechanism between PHPA/Cr(III) acetate, where the metal ions cease to interact with the acetate binder $(R)$ and start to form ionic bonds with the PHPA carboxylates, generating three-dimensional gel structures.

The influence of the hydrolysis degree of PHPA on the occurrence of syneresis in PHPA/Cr(III) hydrogels was studied by Zhang et al. (2015b). For this, hydrogels were prepared with three PHPA samples of the same molecular weight and with 20\%,30\%, and 39\% hydrolysis degree. As polymer hydrolysis increased, more carboxylates were present in the PHPA structure, allowing greater reticulation density of the hydrogel, so the water present in the three-dimensional structure was expelled more easily, generating syneresis, and destabilization of the system. Thus, a higher hydrolysis degree of PHPA provides a higher rate of syneresis.

Sun et al. (2016) developed a system with delayed crosslinker formed by polyacrylamide, thiourea as a stabilizer, sodium carbonate to control the hydrolysis degree, and $\mathrm{Cr}$ (III) acetate. The hydrolysis degree of PAM was controlled at $0.01 \%$ and $0.001 \%$, and the polymer and crosslinker concentrations were $5000 \mathrm{mg} \mathrm{L}^{-1}$ and $500 \mathrm{mg} \mathrm{L}^{-1}$, respectively. At $65{ }^{\circ} \mathrm{C}$, the gelation time increased from 8 to 30 days with the decrease of the hydrolysis degree, giving the system enough time to flow into deeper areas. Thus, this system showed promise for application in locations further from the injection wells (Sun et al., 2016).

Alsheri et al. (2019) studied a gel system formed by sulfonated polyacrylamide and $\mathrm{Cr}$ (III) acetate and evaluated the system's efficiency to seal fracture zones in carbonate rock plugs under high-salinity and hightemperature conditions. The injected gel system was formed by 4000 ppm polymer and 100 ppm $\mathrm{Cr}(\mathrm{III})$ and the tests were performed at $95{ }^{\circ} \mathrm{C}$ in different rock plugs. They verified that the conformance control treatment with this hydrogel was promising, because it provided improvements in the oil recovery factor between $12.0 \%$ and $37.6 \%$.

In general, the gelation time of systems composed of polyacrylamide crosslinked by metal ions depends on the polymer and crosslinker concentration, hydrolysis degree of the polymer, temperature, $\mathrm{pH}$, and salinity. The summary of activities performed with acrylamide-based polymers and inorganic crosslinkers is presented in Table 1. Although many studies have been published, these inorganically crosslinked systems have limitations for application to conformance control of reservoirs with higher temperature and salinity conditions (Bai et al., 2015a; Zhu et al., 2017b). Thus, systems formed by organic crosslinkers have been and are being developed to try to overcome the limitations of crosslinking by multivalent metal ions.

\subsection{Acrylamide-based polymers with organically crosslinked systems}

Gel systems based on polyacrylamide can be formed by crosslinking with organic compounds such as phenolformaldehyde, resorcinol-formaldehyde, hydroquinone hexamethylenetetramine, $\quad N, N^{\prime}$-methylenebisacrylamide Polyethyleneimine (PEI), among others. In these gels, the crosslinks generating the three-dimensional structures are formed by covalent bonds between the amide groups of the polymer and the functional groups of the organic crosslinking agents. Due to the greater stability that covalent bonds give to gels, these systems are promising for application in reservoirs with higher salinity and temperature, and thus, have advantages over metal ion crosslinked systems (Al-Muntasheri et al., 2008a, b; Chung et al., 2011; 
Table 1. Summary of activities performed with acrylamide-based polymers and inorganic crosslinkers.

\begin{tabular}{ll}
\hline Year & \multicolumn{1}{c}{ Activity } \\
\hline 1972 & $\begin{array}{l}\text { Developed the first gel system }- \text { PHPA with a diluted Cr } \\
\text { (III) hydroxide solution }\end{array}$ \\
1982 & $\begin{array}{l}\text { Studied gel system of PHPA crosslinked with aluminum } \\
\text { sulfate and evaluated pH influence }\end{array}$ \\
1974, & $\begin{array}{l}\text { Prepared gel systems with PHPA/Al(III) citrate and } \\
\text { evaluated the effect of citrate ions }\end{array}$ \\
and 1985, & \\
1987 & Analyzed systems based on PHPA/Cr(III) propionate \\
1988 & Patented a new polymer gel system based on \\
& PHPA/Cr(III) acetate
\end{tabular}

1992

Evaluated the resistance of systems formed by PHPA/ $\mathrm{Al}(\mathrm{III})$ citrate

1993

Evaluated the delaying effect of $\mathrm{Cr}(\mathrm{III})$ complexes with glycolate, malonate and salicylate on PAM-AMPS

1994

Applied Cr(III) systems in the Big Horn Basin in Wyoming

1996

Studied the effects of $\mathrm{Al}(\mathrm{III})$ citrate on the gelation time

2001

Developed gel systems with PHPA and Ti(IV) tartrate

2001 ,

Conducted studies with gel systems of

2003 PHPA/Cr(III) acetate

2005 ,

2008 ,

and 2008

2010

Prepared hydrogels with $\mathrm{Cr}(\mathrm{III})$ acetate and PAMAMPS

2014

Evaluated the influence of molecular weight and temperature on $\mathrm{PHPA} / \mathrm{Cr}(\mathrm{III})$ acetate systems

2014

Developed hydrogels formed of PHPA and $\mathrm{Al}(\mathrm{III})$ citrate and evaluated the influence of $\mathrm{pH}$

2014

Formed systems with PAM-AMPS, chromium triacetate and added sodium lactate as a retardant (to increase gelation time) PHPA and $\mathrm{Cr}(\mathrm{III})$ acetate on the syneresis in PHPA/Cr(III) hydrogels

Needham et al.

Ghazalli and Willhite

Moradi-Araghi et al.

Mumallah and Shioyama

Sydansk

Fletcher et al.

Albonico et al.

Southwell and Posey

Stavland and Jonsbraten

Cai and Huang

Grattoni et al.

Seright et al.

Cheng et al.

Vargas-Vasquez and Romero-Zerón

Romero-Zerón et al.

Koohi et al.

Dang et al.

Kedir et al.

Moghagam et al.

Zhang et al.

Zhang et al.

Sun et al. 
Ghriga et al., 2019; Yavari-Gohar et al., 2010; Zhu et al., 2017c).

These gels are called Organically Crosslinked Gels (OCGs) and for their formation, the polyacrylamide can be used in its homopolymer (PAM), partially hydrolyzed (PHPA) or copolymerized form, such as: PAM-NVP, PAM-AMPS or PAM-tBA. The viscoelastic properties of OCG, gelation time, thermal stability, and salinity resistance are determined by the composition of these systems (Bai et al., 2015a; Chung et al., 2011; Jayakumar and Lane, 2013).

The first gels formed by organic crosslinking agents were developed by Chang et al. (1984), who produced gel systems based on polyacrylamide crosslinked by resorcinolformaldehyde and phenol-formaldehyde. After this study, Moradi-Araghi (1993), Bryant et al. (1997), MoradiAraghi (2000), and other researchers developed phenolformaldehyde crosslinked systems. The authors verified that the gelling mechanism was formed by the reaction product of phenol with formaldehyde and the amide groups of the polymer, observing the formation of stable gels. According Moradi-Araghi (1993), the gels produced with $1 \% \mathrm{w} / \mathrm{v}$ polymer in the formation water remained stable for 13 years at aging temperature of $121^{\circ} \mathrm{C}$.

Although these systems have been applied in several reservoir conformance treatments and have shown satisfactory results, this organic crosslinking agent is now less used due to the high toxicity of phenol, and mainly the carcinogenic characteristic of formaldehyde (Chung et al., 2011; Moradi-Araghi, 2000).

Thus, researchers began to develop crosslinking systems composed of Hydroquinone (HQ) and Hexamethylenetetramine (HMTA) to replace phenol-formaldehyde and remedy the problems caused by its use. HMTA is a less toxic derivative of formaldehyde and the HQ in high concentrations is harmful to aquatic life. However, the crosslinking systems formed by these two components are less toxic than phenol-formaldehyde (Liu et al., 2016; Sengupta et al., 2012).

Hutchins et al. (1996) were the first to produce and report the application of polyacrylamide gels crosslinked with HQ-HMTA for use in high temperature reservoirs. These systems showed good gelling properties, with stability at $149{ }^{\circ} \mathrm{C}$ for 1 year and at $176.7{ }^{\circ} \mathrm{C}$ for 5 months. The authors considered them to be highly applicable for conformance control in high permeability areas. Dovan et al. (1997) also studied these systems and observed that the gels had a long gelation time and better thermal stability than those crosslinked by phenol-formaldehyde.

Sengupta et al. (2012) conducted studies of the properties of gels formed by polyacrylamide and hydroquinonehexamethylenetetramine and verified the formation of gels with high mechanical resistance at $120{ }^{\circ} \mathrm{C}$ and that the ideal $\mathrm{pH}$ value for this was 9.5.

Yadav and Mahto (2013a, b) studied the gelling kinetics and rheological properties of gels formed by PHPA/ HQ-HMTA. They observed that the rheological behavior varied over time, because the viscosity of the system became higher as the gelation time increased due to the formation of crosslinks, while this time decreased with the increase in gel concentration of HQ-HMTA.
Yadav and Mahto (2013c), Sengupta et al. (2014), and Liu et al. (2016) investigated the influence of polymer and crosslinking concentration, temperature, salinity and $\mathrm{pH}$ value on gelation time and gel strength in PAM/ HQ-HMTA systems. According to Liu et al. (2016), the hydrogels formed by $6000 \mathrm{mg} \mathrm{L}^{-1} \mathrm{PAM}$, and $6000 \mathrm{mg} \mathrm{L}^{-1}$ HQ-HMTA showed high thermal stability and can be applied in reservoirs with temperatures up to $140{ }^{\circ} \mathrm{C}$.

In a more recent study, Fang et al. (2017) developed gel systems with PHPA and HQ-HMTA with resistance to High Temperature and Salinity (HTHS) conditions. The authors observed that the gel strength increased and gelation time decreased for higher polymer and crosslinker concentration and higher temperature. They also found that these systems had good injectivity and flowed selectively to the zones of greater permeability.

In order to use organic crosslinkers considered to be environmentally friendly, Polyethyleneimine (PEI) is now used for polyacrylamide-based hydrogels, and it have been successfully applied in several oil fields, due to the formation of stable systems in a wide temperature range. This organic crosslinking agent has become the most widely used in the world during the last decade (Al-Muntasheri et al., 2008b; Zhao et al., 2011).

In general, the crosslinking mechanism of PEI with polyacrylamide and its derivatives occurs via a transamidation reaction. In this reaction, the imine nitrogen of PEI performs a nucleophilic attack on the amide carbonyl group of PAM, replacing a substitution of the amide group, forming covalent bonds between the crosslinks and the main polymer chain (Al-Muntasheri, 2012; Jia et al., 2012; Zhao et al., 2011). The mechanism of this reaction using PEI as a crosslinking agent can be seen in Figure 4.

The first system stable crosslinked by PEI was described by Hardy et al. (1999), who produced a gel system formed of acrylamide/butyl acrylate copolymer and polyethyleneimine (PAM-tBA/PEI). Hardy et al. (1998, 1999) also studied PAM-tBA/PEI gels, where the gelation kinetics of the system was observed along with the effect of $\mathrm{pH}$ variation on the crosslinking time, showing a slight increase at higher $\mathrm{pH}$ values. The excellent propagation and thermal stability of these systems were verified and thus began to be developed for commercial use.

Hardy et al. (1999) observed that the ester groups of the PAM-tBA copolymer may undergo hydrolysis or thermolysis according to $\mathrm{pH}$ and temperature conditions. At low $\mathrm{pH}$, these groups hydrolyze forming PHPA and $t$-butyl alcohol. At high $\mathrm{pH}$ and temperature, the copolymer undergoes thermolysis, producing PHPA, and isobutene. In these cases, crosslinking occurs by nucleophilic attack of the imine nitrogen of the carbonyl carbon on the ester group. However, the crosslinking occurs only at temperatures below $100{ }^{\circ} \mathrm{C}$ and reaction times below $20 \mathrm{~h}$.

Al-Muntasheri et al. (2007) investigated the viscoelastic properties of gels formed by PAM-tBA $(3-7 \% \mathrm{w} / \mathrm{v})$ and PEI with a molecular weight of $70000 \mathrm{~g} / \mathrm{mol}$ $(0.3-1.2 \% \mathrm{w} / \mathrm{v})$, in injection water, saline water of $5000 \mathrm{ppm}$ TDS and distilled water at a temperature of $150{ }^{\circ} \mathrm{C}$ and aging for 30 days. An increase in elastic modulus $\left(\mathrm{G}^{\prime}\right)$ and a decrease in gelation time were observed for higher 


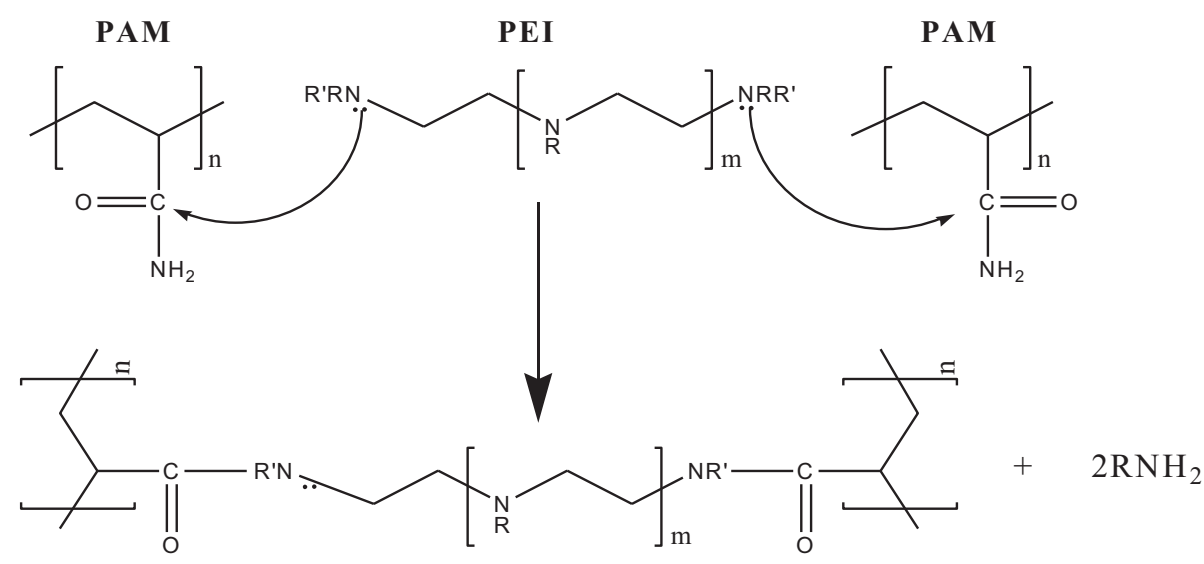

Fig. 4. PHPA-PEI systems' crosslinking mechanism.

crosslinking and polymer concentrations, but for these same concentrations (7 wt\% PAM-tBA and $1.2 \% \mathrm{PEI})$, syneresis was observed at 30 days, reducing $\mathrm{G}^{\prime}$ values by $53 \%$. They also observed that increasing salinity provided a longer gelation time and decreased elastic modulus.

Al-Muntasheri et al. (2008b) prepared PEI-crosslinked PAM hydrogels and studied gelling kinetics under High Temperature $\left(100-140^{\circ} \mathrm{C}\right.$ ) and Pressure (30 Bar) (HTHP) conditions, evaluating the effect of temperature, and salinity. For this purpose, gel systems were prepared with $7 \%$ mass of PAM and $0.3 \%$ PEI in distilled water, brine of 30000 and $50000 \mathrm{mg} \mathrm{L}^{-1}$ TDS of $\mathrm{NaCl}$. They observed that temperature is an extremely important factor for the gelling kinetics of PAM/PEI systems and its increase promoted a decrease in gelation time, with gelling time of $0.67 \mathrm{~h}$ for systems produced with water and times of 4.4 and $6.8 \mathrm{~h}$ for systems produced with $30 \quad 000$ and $50000 \mathrm{mg} \mathrm{L}^{-1} \mathrm{NaCl}$, respectively. This indicates that the gelation time increases for systems with larger amounts of $\mathrm{NaCl}$ in brine, suggesting that this salt may be used as a delayed gelling agent in high temperature reservoirs.

Al-Muntasheri et al. (2009) performed a comparative study between the gelling process of PAM/PEI and PAM-tBA/PEI systems, using $7 \%$ mass of polymer and $1 \%$ mass of PEI, distilled water and aging at $120^{\circ} \mathrm{C}$. They observed that the gelation time of PAM/PEI (13.5 min) was shorter than that of PAM-tBA/PEI (28 min), indicating greater availability of reaction sites in PAM than in PAM-tBA. These systems were not suitable for application in reservoirs due to their fast gelation time, but this could be adjusted by reducing polymer and/or crosslinking concentrations.

Jia et al. (2010) investigated the influence of polymer concentration and molecular weight on the formation of PHPA/PEI gels. Systems containing $0.5 \%$ to $1.5 \%$ by mass PHPA (with weight-average molecular weights of 2000, 4000, and $8000 \mathrm{~kg} / \mathrm{mol}$ ) were prepared with $1 \%$ PEI, brine with $9000 \mathrm{mg} \mathrm{L}^{-1} \mathrm{TDS}$ at a temperature of $40{ }^{\circ} \mathrm{C}$. They observed that with increasing polymer concentration, the number of crosslinking points in the polymer increased, raising the crosslinking rate and consequently reducing the gelation time. Regarding molecular weight, a slight decrease in gelation time and a small increase in gel strength were considered for systems produced with greater molecular weight.

In another study, Jia et al. (2012) concluded that the main factors that influence gelling performance are polymer concentration, crosslinking concentration, PHPA molecular weight, and Total Dissolved Salts (TDS) in the water used to prepare the systems.

Zhao et al. (2011) investigated the performance of PHPA/PEI systems to seal fractured regions and found that the gel formed by $2 \%$ mass of PHPA $\left(M_{w}=8000 \mathrm{~kg} / \mathrm{mol}\right)$, $0.35 \%$ mass of PEI $\left(M_{w}=20 \mathrm{~kg} / \mathrm{mol}\right)$ in brines of $5000 \mathrm{mg} \mathrm{L^{-1 }}$ TDS. This system was a promising blocking agent for use in fractured reservoirs with temperature of $65{ }^{\circ} \mathrm{C}$, as it presented high mechanical performance and resisted the maximum pressure gradient of $1136.38 \mathrm{psi} / \mathrm{ft}$ in cores with fractures from $0.080 \mathrm{~cm}$ to $0.200 \mathrm{~cm}$.

Jayakumar and Lane (2012) developed a delayed gelling system consisting of PHPA and a mixture of PEI and dextran sulfate. They noted that the PEI was available for crosslinking with the polymers only when its interaction with dextran sulfate was interrupted, increasing the gelation time. However, this delaying agent is very expensive and its use on a commercial scale for reservoirs has become unfeasible.

Thus, Jayakumar and Lane (2013) replaced the use of dextran sulfate with 2-acrylamid-methylpropane sulfonic acid, since it is cheaper, easily available and widely used in oil fields, and studied the delayed gelling system formed by PHPA-PEI-AMPS. They observed that $\mathrm{PEI} / \mathrm{AMPS}$ was an effective crosslinking retardant agent because in systems containing $0.4 \%$ mass of crosslinked PHPA with $0.4 \%$ PEI, the gelation time was $13 \mathrm{~h}$ but when crosslinked by $0.4 \%$ PEI:AMPS retardant system in the ratio of $2: 1$, this time increased to $120 \mathrm{~h}$, showing the efficiency of the process. In addition, the decrease in the PEI:AMPS ratio promoted a longer delay of the gelling process.

El-Karsani et al. (2014b, c) prepared systems with $7 \%$ mass of PAM cross-linked by $0.3 \%$ PEI, in distilled water with the addition of $12000 \mathrm{ppm}$ of $\mathrm{NaCl}$ or $\mathrm{NH}_{4} \mathrm{Cl}$ and in formation water with the same quantities and types of added salts in distilled water, and studied the effect of these different salts on gelling retardation and gel strength, 
comparing the action of $\mathrm{NaCl}$ and $\mathrm{NH}_{4} \mathrm{Cl}$. They noted that both in distilled water and in formation water, the addition of salts promoted the delay of gel formation and a slight decrease in gel strength. The use of $\mathrm{NH}_{4} \mathrm{Cl}$ caused this effect to occur more markedly than the addition of $\mathrm{NaCl}$ (El-Karsani et al., 2014c).

According to Bai et al. (2015b), gel systems can also be prepared with Hydrophobically Associated Polyacrylamide (HAP), when it contains one or more hydrophilic groups and a small number of hydrophobic groups. Thus, the systems were prepared with $0.35 \% \mathrm{w} / \mathrm{w}$ HAP $(12000 \mathrm{~kg} / \mathrm{mol}$ molecular weight) and $0.60 \%$ PEI $(12 \mathrm{~kg} / \mathrm{mol})$ at $80{ }^{\circ} \mathrm{C}$. This HAP/PEI system formed a gel with good stability and gelation time of $45 \mathrm{~h}$, which could be delayed by the addition of $\mathrm{CaCl}_{2}$ and $\mathrm{NaCl}$ or by lowering the temperature.

Hashmat et al. (2016) studied systems formed by PHPA with hydrolysis degree of 25-30\% and molecular weight of $8000 \mathrm{~kg} / \mathrm{mol}$ (commercially known as Flopaam 3330S) and an anionic copolymer based on polyacrylamide with the commercial name Alcomer 130 (A130), with molecular weight considered ultra-high compared to Flopaam 3330, with crosslinking by PEI. Thus, the systems were prepared with $3 \% 3330$ S polymer, $0.6 \%, 1.0 \%$ and $1.2 \%$ PEI, and $2 \%$ A130 polymer with the same amount of PEI. The thermal stability of these systems was studied at $100{ }^{\circ} \mathrm{C}$ for 28 days of aging.

According to the authors, it is essential to study the thermal stability of gels due to the polymer, which can undergo hydrolysis at high temperatures, resulting in the syneresis of the gel system, with a significant reduction in the gel volume. A thermally stable gel does not undergo syneresis, and consequently shows few signs of gel retraction. Thus, all systems prepared for that study with 3330S and A130 remained stable, with no significant retraction in volume, and formation of rigid and non-fluid gels (Hashmat et al., 2016).

Zhang et al. (2017) produced a terpolymer formed by 2-acrylamide-2-tetradecyl ethyl sulfonic acid (AMC16S), Acrylamide (AM) and Acrylic Acid (AA), with temperature resistance of $100{ }^{\circ} \mathrm{C}$, indicating that it might be suitable to form gels. This acrylamide-based terpolymer was crosslinked by PEI and its properties were studied to apply this gel in conformance control of high temperature reservoirs. According to the authors, the gel systems formed by $3000 \mathrm{mg} \mathrm{L}^{-1}$ terpolymer and $2000 \mathrm{mg} \mathrm{L}^{-1}$ PEI slowed gelation time, and gel strength was affected by salinity, $\mathrm{pH}$ and temperature conditions. In addition, this system showed good shear resistance, ensuring that the gel system was not destroyed during transport through the porous formation and had thermal stability for a long period. Thus, these systems can be used as blocking gels in deeper regions of the reservoir.

Ma et al. (2017) developed systems composed of PHPA, PEI and Silica Nanoparticles (SNP) in order to improve the performance of gels. Systems were prepared with $1 \% \mathrm{w} / \mathrm{w}$ of PHPA, $0.2 \% \mathrm{w} / \mathrm{w}$ of PEI and $0.63 \% \mathrm{w} / \mathrm{w}$ of SNP with diameters of 9-12 $\mathrm{nm}$ in formation water with $53200 \mathrm{mg} \mathrm{L}^{-1}$ TDS. They performed a comparative study of PHPA/PEI and PHPA/PEI-SNP gels. The gelation time of the PHPA/PEI system was approximately $30 \mathrm{~h}$ and with the addition of SNP this time was extended to
$132 \mathrm{~h}$. The strength of the PHPA/PEI-SNP gel remained the same as that of the PHPA/PEI system and showed excellent thermal stability at $85{ }^{\circ} \mathrm{C}$ for 28 days, without presenting syneresis, unlike the PHPA/PEI system, which presented dehydration after aging for 17 days.

Chen et al. (2018) developed PAM-PEI systems reinforced with nanosilica having particle size of $28.6 \mathrm{~nm}$, with varying nanoparticle concentrations $(0 \%, 0.1 \%, 0.3 \%$, and $1 \%$ by mass), to verify the reinforcement and stabilizing power. They observed that the increased in nanosilica concentration provided higher gel strength, shorter gelation time and greater stability of the systems. Hydrogels without nanosilica remained stable (without syneresis) at $130{ }^{\circ} \mathrm{C}$ for 18 days, increasing to 35 days with $0.1 \%$, 65 days with $0.3 \%$ and 180 days with $1 \%$ nanosilica. When comparing the microstructure of nanocomposite hydrogels with the common one, a denser and stronger three-dimensional network was observed. Thus, it can be inferred that the silanol group of the nanoparticle formed crosslinks with the hydrogen of the amide group of PAM by hydrogen bonds, providing reinforcement in the hydrogel structure.

Lashari et al. (2018) also studied the action of nanosilica as a reinforcement filler in systems formed by polymer based on polyacrylamide crosslinked by resorcinolhexamethylenetetramine, at temperature of $100{ }^{\circ} \mathrm{C}$ and salinity $51984 \mathrm{ppm}$ TDS. They observed improved thermal stability (no syneresis) for about 90 days and increased gel strength.

Jia and Chen (2018) developed gel systems with multiple crosslinking of PHPA, $\mathrm{Cr}(\mathrm{III})$ acetate, and polyethyleneimine $\left(\mathrm{Cr}^{3+}-\right.$ PEI-PHPA), in order to study the gelling behavior and improve the properties. For the crosslinked systems with $\mathrm{Cr}^{3+}$, they noted the formation of a weak gel ("pre linked gel"), which showed good pumping capacity and reduced adsorption of polymer in the plugs, ensuring good gelling performance. When increasing the temperature during the pumping process, second-stage crosslinking took place, with the formation of covalent bonds with PEI, generating high gel strength, applicable for conformance control.

Adewunmi et al. (2018) used Coal Fly Ash (CFA) as an additive to improve the properties of hydrogels. This material is obtained from burning coal and consists mainly of alumina and silica. The authors prepared PHPA-PEI and PHPA-PEI-CFA hydrogels, with nanofiller concentrations of $0.5 \%, 1 \%$ and $2 \% \mathrm{w} / \mathrm{w}$. From rheological analyses they found that PAM-PEI-CFA hydrogels showed more elastic behavior than PAM-PEI hydrogels, indicating the CFA's dispersion and strengthening effect. This reinforcement was stronger with increasing load content. In addition, the nanocomposite hydrogel with $2 \%$ CFA was subjected to tests to simulate the action as sealant of fracture zones in reservoir rocks to evaluate the effectiveness of gel blocking at a temperature of $90{ }^{\circ} \mathrm{C}$. The result showed considerable sealing power.

Zhu et al. (2019) studied the effects of polymer and crosslinker concentration, PEI molecular weight and salinity on the gelation performance of hydrogels formed by terpolymer (AM-AMPS-NVP) and crosslinked by polyethyleneimine at $150{ }^{\circ} \mathrm{C}$. They found that polymer 
Table 2. Summary of activities performed with acrylamide-based polymers and organic crosslinkers.

\begin{tabular}{|c|c|c|}
\hline Year & Activity & Authors \\
\hline 1984 & $\begin{array}{l}\text { Formation of the first gels by organic crosslinking - } \\
\text { PAM/resorcinol-formaldehyde and PAM/phenol-formaldehyde }\end{array}$ & Chang et al. \\
\hline 1993 & Developed phenol-formaldehyde crosslinked systems & Moradi-Araghi \\
\hline 1996 & $\begin{array}{l}\text { Produced and reported the application of PAM gels crosslinked with } \\
\text { HQ-HMTA for use in high-temperature reservoirs }\end{array}$ & Hutchins et al. \\
\hline 1997 & $\begin{array}{l}\text { Observed a long gelation time and thermal stability of } \\
\text { PAM/HQ-HMTA systems }\end{array}$ & Dovan et al. \\
\hline 1997 & Developed phenol-formaldehyde systems & Bryant et al. \\
\hline 1998 and 1999 & Produced the first stable crosslinked by PEI & Hardy et al. \\
\hline 2000 & Developed phenol-formaldehyde crosslinked systems & Moradi-Araghi \\
\hline 2007 & $\begin{array}{l}\text { Investigated the viscoelastic properties of gels formed by PAM-tBA } \\
\text { and PEI }\end{array}$ & Al-Muntasheri et al. \\
\hline $2008 b$ & Studied gelling kinetics of PAM/PEI systems under HTHP conditions & Al-Muntasheri et al. \\
\hline 2009 & $\begin{array}{l}\text { Developed a comparative study between PAM/PEI and PAM-tBA/ } \\
\text { PEI }\end{array}$ & Al-Muntasheri et al. \\
\hline 2010 & $\begin{array}{l}\text { Investigated the influence of polymer concentration and molecular } \\
\text { weight on PHPA/PEI hydrogels }\end{array}$ & Jia et al. \\
\hline 2011 & Evaluated the performance of PHPA/PEI systems & Zhao et al. \\
\hline 2012 & Conducted studies of the properties of PAM/HQ-HMTA hydrogels & Sengupta et al. \\
\hline 2012 & $\begin{array}{l}\text { Concluded that several factors influence the gelling performance of } \\
\text { PHPA/PEI systems }\end{array}$ & Jia et al. \\
\hline 2012 & $\begin{array}{l}\text { Developed a delayed gel system consisting of PHPA, PEI, and dextran } \\
\text { sulfate }\end{array}$ & Jayakumar and Lane \\
\hline $2013 \mathrm{a}, \mathrm{b}$ & Studied the gelling kinetics of gels formed by PHPA/HQ-HMTA & Yadav and Mahto \\
\hline 2013 & Developed gel systems with PHPA, PEI and AMPS & Jayakumar and Lane \\
\hline 2014 & $\begin{array}{l}\text { Investigated the influence of several factors on PAM/HQ-HMTA } \\
\text { systems }\end{array}$ & Sengupta et al. \\
\hline 2014b, c & Evaluated the action of $\mathrm{NaCl}$ and $\mathrm{NH}_{4} \mathrm{Cl}$ in $\mathrm{PAM} / \mathrm{PEI}$ systems & El-Karsani et al. \\
\hline $2015 b$ & $\begin{array}{l}\text { Prepared systems with hydrophobically associated polyacrylamide } \\
\text { and PEI }\end{array}$ & Bai et al. \\
\hline 2016 & $\begin{array}{l}\text { Investigated the influence of several factors on PAM/HQ-HMTA } \\
\text { systems }\end{array}$ & Liu et al. \\
\hline 2016 & Studied systems formed by PHPA and PEI & Hashmat et al. \\
\hline 2017 & $\begin{array}{l}\text { Developed PHPA/HQ-HMTA gel systems with resistance to HTHS } \\
\text { conditions }\end{array}$ & Fang et al. \\
\hline 2017 & $\begin{array}{l}\text { Produced gel systems formed by a terpolymer of AM, AA and } \\
\text { AMC16S, crosslinked by PEI }\end{array}$ & Zhang et al. \\
\hline 2017 & Developed systems composed of PHPA, PEI and silica nanoparticles & Ma et al. \\
\hline
\end{tabular}


Table 2. (Continued)

\begin{tabular}{|c|c|c|}
\hline Year & Activity & Authors \\
\hline 2018 & Developed PAM-PEI systems reinforced with nanosilica & Chen et al. \\
\hline 2018 & $\begin{array}{l}\text { Studied the action of nanosilica as a reinforcement filler in PAM/ } \\
\text { resorcinol-HMTA systems }\end{array}$ & Lashari et al. \\
\hline 2018 & $\begin{array}{l}\text { Developed gel systems with multiple crosslinking, formed by PHPA, } \\
\text { Cr(III) acetate and PEI }\end{array}$ & Jia and Chen \\
\hline 2018 & Developed PHPA/PEI systems reinforced with coal fly ash & Adewunmi et al. \\
\hline 2019 & $\begin{array}{l}\text { Studied the effects of several factors on the gelation performance of } \\
\text { hydrogels formed by terpolymer (AM-AMPS-NVP) and PEI }\end{array}$ & Zhu et al. \\
\hline 2019 & $\begin{array}{l}\text { Evaluated systems formed by acrylamide-based polymers, PEI, and } \\
\text { bentonite }\end{array}$ & Tessarolli et al. \\
\hline
\end{tabular}

concentration had a strong influence on the gelation time and the gel strength, since the increase of the terpolymer concentration provided a larger number of sites available for crosslinking, reducing the gelation time and forming stronger hydrogels. The concentration of PEI had an effect similar to the polymer concentration, but less intense. Furthermore, they observed that the molar mass of PEI influenced crosslinking, enabling obtaining hydrogels only in systems produced with PEI with molar masses above $3000 \mathrm{~g} / \mathrm{mol}$. The addition of salts slightly shortened the gelation time, and thermally stable gel systems could be obtained at $150{ }^{\circ} \mathrm{C}$.

Tessarolli et al. (2019) studied systems formed by acrylamide-based polymers, PEI, and bentonite and evaluated the influence of the polymeric structure on gel strength and gelation kinetics. For this, the following polymers were tested: PAM, HPAM, PAM-AMPS and PAM-AMPS-NVP. The chemical structure of the polymer had a strong influence on the properties. Systems with higher amounts of AMPS or acrylate groups and higher molar masses had greater gel strength and shorter gelation time. Systems with more NVP groups or higher bentonite content had longer gelation time and higher gel strength. Furthermore, the most promising system for application in conformance control was produced with the PAM-AMPS-NVP terpolymer.

The summary of activities performed with acrylamidebased polymers and organic crosslinkers is presented in Table 2. In general, hydrogels formed from organic crosslinkers have advantages over inorganic crosslinking and can be used for conformance control of oil reservoirs with higher temperatures.

\section{Conclusion}

Conformance control is a key to the EOR method because it stimulates the sweeping of oil in a well-distributed manner in reservoirs. In this technique, the use of gel systems based on polyacrylamide stands out, because they form impermeable hydrogels in situ in areas of greater permeability, obstructing the preferred paths in the rock matrix, and providing greater efficiency in oil recovery. These systems must present good injectivity, low adsorption of their components in the porous medium, controlled gelation time, and stability in the reservoir conditions.

These hydrogels are produced from crosslinking between the polymer and inorganic (metallic ions) or organic crosslinking agents. In systems crosslinked by metallic ions, the formation of the hydrogels occurs by ionic bonds between the negative charges of the polymer carboxylates groups and the multivalent cations, with chromium (III) being used most, generally in the form of chromium acetate (III).

In organically reticulated systems, there are covalent bonds between the amide groups of the polymer and the functional groups of the organic crosslinker. In this case, the use of polyethyleneimine is best because it causes less severe environmental impacts. Due to the greater stability of the crosslinks, these hydrogels have advantages in relation to metal ion crosslinked hydrogels and can be used for conformance control of oil reservoirs with higher temperatures. In general, these systems have gelation time, gel strength, and stability depending on the polymer and crosslinker concentration, molecular weight, degree of polymer hydrolysis, temperature, $\mathrm{pH}$, and salinity.

These gel systems may present limitations for application in reservoirs with severe salinity and temperature conditions. In view of this, nanofillers have been used, generating nanocomposite hydrogels. The results have been promising, with the formation of hydrogels with better mechanical properties and good stability in reservoir conditions.

Acknowledgments. We thank CNPq for support.

\section{References}

Adewunmi A.A., Ismail S., Sultan A.S. (2018) Crosslinked polyacrylamide composite hydrogels impregnated with fly ash: Synthesis, characterization and their application as fractures 
sealant for high water producing zones in oil and gas wells, $J$. Polym. Environ. 12, 1-13. doi: 10.1007/s10924-018-1204-9.

Albonico P., Burrafato G., Di-Lullo A., Lockhart T.P. (1993) Effective gelation-delaying additives for $\mathrm{Cr}^{3+} /$ Polymer gels, in: SPE International Symposium on Oilfield Chemistry, 2-5 March 1993, New Orleans, LA. doi: 10.2118/25221-MS

Alfarge D., Wei M., Bai B., Almansour A. (2018) Numerical simulation study to understand the performance of RPM gels in water-shuttoff treatments, J. Pet. Sci. Eng. 171, 818-834. doi: $10.1016 /$ j.petrol.2018.07.082.

Ali A.S. (2010) Mature fields and well revitalization, J. Pet. Technol. 62, 1, 1-2. doi: 10.2118/0110-0048-JPT.

Al-Muntasheri G.A. (2012) Conformance control with polymer gels: What it takes to be successful, Arab. J. Sci. Eng. 37, 4, 1131-1141. doi: 10.1007/s13369-012-0234-1.

Al-Muntasheri G.A., Hussein I.A., Nasr-El-Din H.A., Amin M.B. (2007) Viscoelastic properties of a high temperature crosslinked water shut-off polymeric gel, J. Pet. Sci. Eng. 55, 2, 56-66. doi: 10.1016/j.petrol.2006.04.004.

Al-Muntasheri G.A., Nasr-El-Din H.A., Peters J.A., Zitha P.L.J. (2008a) Thermal decomposition and hydrolysis of polyacrylamide-co-tert-butyl acrylate, Eur. Polym. J. 44, 4, 1225-1237. doi: 10.1016/j.eurpolymj.2008.01.022.

Al-Muntasheri G.A., Nasr-El-Din H.A., Zitha P.L.J. (2008b) Gelation kinetics and performance evaluation of an organically crosslinked gel at high temperatures and pressure, SPE J. 13, 3, 337-345. doi: 10.2118/104071-PA.

Al-Muntasheri G.A., Nasr-El-Din H.A., Al-Noaimi K., Zitha P.L.J. (2009) A study of polyacrylamide-based gels crosslinked with polyethyleneimine, SPE J. 14, 2, 245-251. doi: 10.2118/105925-PA.

Al-Nakhli A., Al-Muntasheri G., Al-Harith A., Balharth S. (2013) Benchmarking RPMs performance to reduce water-oil ratio of produced fluids from carbonate formations, in: $S P E$ Saudi Arabia Section Technical Symposium and Exhibition, 19-22 May, Al-Khobar, Saudi Arabia. SPE-168085-MS. doi: 10.2118/168085-MS

Alsheri A.J., Wang J., Kwak H.T., Alsofi A.M., Gao J. (2019) A study of gel-based conformance control within fractured carbonate cores using low-field nuclear-magnetic-resonance techniques, Soc. Pet. Eng. 22, 3, 1-12. doi: 10.2118/187397-PA.

American Petroleum Institute (1982) The sources, chemistry, fate, and effects of chromium in aquatic environments, Washington, DC, $191 \mathrm{p}$.

Bai B., Zhou J., Yin M. (2015a) A comprehensive review of polyacrylamide polymer gels for conformance control, Petrol. Explor. Dev. 42, 4, 525-532. doi: 10.1016/S1876-3804(15)30045-8.

Bai Y., Xiong C., Wei F., Li J., Shu Y., Liu D. (2015b) Gelation Study on a hydrophobically associating polymer/polyethylenimine gel system for water shut-off treatment, Energy Fuels 29, 2, 447-458. doi: 10.1021/ef502505k.

Bryant S.L., Borghi G.P., Bartosek M., Lockhart T.P. (1997) Experimental investigation on the injectivity of phenolformaldehyde/polymer gelants, Society of Petroleum Engineers, Houston, TX.

Cai W., Huang R. (2001) Study on gelation of partially hydrolyzed polyacrylamide with titanium (IV), Eur. Polym. J. 37, 8, 1553-1559, ago. 2001. doi: 10.1016/S0014-3057(01)00041-6.

Chang P., Gruetzmacher G., Meltz C., Totino R. (1984) Enhanced hydrocarbon recovery by permeability modification with phenolic gels. US4708974A, 01 out. 1984.

Chen L., Wang J., Yu L., Zhang Q., Fu M., Zhao Z., Zuo J. (2018) Experimental investigation on nano-silica reinforcing
PAM/PEI hydrogel for water shutoff treatment, Energy Fuels 33, 1, 1-16. doi: 10.1021/acs.energyfuels.8b00840.

Cheng M., Wang C., Mccool C.S., Green D.W., Willhite G.P. (2005) Modeling of pre-gel aggregate growth during the gelation of polyacrylamide-chromium (III) acetate gel system using the theory of branching processes, Society of Petroleum Engineers, The Woodlands, TX.

Chung T., Bae W., Nguyen N.T.B., Dang C.T.Q., Lee W., Jung B. (2011) A review of polymer conformance treatment: A successful guideline for water control in mature fields, Energy Sources Part A Recovery Utilization Env. Eff. Londres 34, 2, 122-133. doi: 10.1080/15567030903567683.

Dang T.Q.C., Chen Z., Nguyen T.B.N., Bae W., Chung T., Tu T.N. (2014) The development and optimization of a polymer conformance control technology in mature reservoirs: Laboratory experiments vs. field scale simulation, Energy Sources Part A Recovery Utilization Env. Effects 36, 11, 1219-1233. doi: $10.1080 / 15567036.2010 .551259$.

Dovan H.T., Hutchins R.D., Sandiford B.B. (1997) Delaying gelation of aqueous polymer at elevated temperatures using novel organic crosslinkers, Society of Petroleum Engineers, Houston, TX.

El-Hoshoudy A.N., Desouky S.E.M., Elkady M.Y., Al-Sabagh A. M., Betiha M.A., Mahmoud S. (2017) Hydrophobically associated polymers for wettability alteration and enhanced oil recovery - Article review, Egypt. J. Pet. 26, 3, 757-762. doi: 10.1016/j.ejpe.2016.10.008.

El-Karsani K.S.M., Al-Muntasheri G.A., Hussein I.A. (2014a) Polymer Systems for water shutoff and profile modification: A review over the last decade, SPE J. 19, 1, 135-149. doi: 10.2118/163100-PA.

El-Karsani K.S.M., Al-Muntasheri G.A., Sultan A.S., Hussein I.A. (2014b) Gelation kinetics of PAM/PEI system: DSC investigation, J. Therm. Anal. Calorim. 116, 3, 1409-1415. doi: 10.1007/s10973-014-3754-y.

El-Karsani K.S.M., Al-Muntasheri G.A., Sultan A.S., Hussein I.A. (2014c) Gelation of a water-shutoff gel at high pressure and high temperature: Rheological investigation, SPE J. 20, 5, 1-10.

Fang J., Zhang X., He L., Zhao G., Dai C. (2017) Experimental research of hydroquinone (HQ)/hexamethylene tetramine (HMTA) gel for water plugging treatments in hightemperature and high-salinity reservoirs, J. Appl. Polym. Sci. 134, 1, 44359-44367. doi: 10.1002/app.44359.

Fletcher A.J.P., Flew S., Forsdyke I.N., Morgan J.C., Rogers C., Suttles D. (1992) Deep diverting gels for very cost-effective waterflood control, J. Pet. Sci. Eng. 7, 1, 33-43.

Ghazalli H.A., Willhite G.P. (1985) Permeability modification using aluminum citrate/polymer treatments: Mechanisms of permeability reduction in sandpacks, Society of Petroleum Engineers, Phoenix, AZ.

Ghriga M.A., Grassl B., Gareche M., Khodja M., Lebouachera S. E.I., Andreu N., Drouiche N. (2019) Review of recent advances in polyethylenimine crosslinked polymer gels used for conformance control applications, Polym. Bull. 76, 11, 6001-6029. doi: 10.1007/s00289-019-02687-1.

Goudarzi A., Zhang H., Varavei A., Taksaudom P., Hu Y., Delshad M., Bai B., Sepehrnoori K. (2015) A laboratory and simulation study of preformed particle gels for water conformance control, Fuel 140, 502-513. doi: 10.1016/j.fuel.2014.09.081.

Grattoni C.A., Al-Sharji H.H., Yang C., Muggeridge A.H., Zimmerman R.W. (2001) Rheology and permeability of crosslinked polyacrylamide gel, J. Colloid Interface Sci. 240, 2, 601-607. 
Guan H., Berkland C., Moradi-Araghi A., Liang J.-T., Christian T., Needham R., Cheng M., Scully F.L., Hedges J. (2014) Nanogels for delayed gelation. US20140202693 A1, 30 dez. 2013, 24 jul. 2014.

Hardy M.B., Botermans C.W., Smith P. (1998) New organically crosslinked polymer system provides competent propagation at high temperature in conformance treatments, in: SPE/DOE Improved Oil Recovery Symposium, 19-22 April, Tulsa, $O K$.

Hardy M., Botermans W., Hamouda A., Valdal J., Warren J. (1999) The first carbonate field application of a new organically crosslinked water shutoff polymer system, Society of Petroleum Engineers, Houston, TX, pp. 16-19. doi: 10.2118/50738-MS.

Hashmat M.D., Sultan A.S., Rahman S., Hussain S.M.S. (2016) Crosslinked polymeric gels as loss circulation materials: An experimental study, Society of Petroleum Engineers, Arábia Saudita. doi: 10.2118/182740-MS.

Hutchins R.D., Dovan H.T., Sandiford B.B. (1996) Field applications of high temperature organic gels for water control, Society of Petroleum Engineers, Tulsa, OK.

Imqam A., Bai B. (2015) Optimizing the strength and size of preformed particle gels for better conformance control treatment, Fuel 148, 178-185. doi: 10.1016/j.fuel.2015.01.022.

Jayakumar S., Lane R.H. (2012) Delayed crosslink polymer flowing gel system for water shutoff in conventional and unconventional oil and gas reservoirs, Society of Petroleum Engineers, Lafayette, LA. doi: 10.2118/151699-MS.

Jayakumar S., Lane R.H. (2013) Delayed crosslink polymer gel system for water shutoff in conventional and unconventional oil and gas reservoirs, Society of Petroleum Engineers, The Woodlands, TX. doi: 10.2118/164046-MS.

Jia H., Chen H. (2018) Using DSC technique to investigate the non-isothermal gelation kinetics of the multi-crosslinked chromium acetate $\left(\mathrm{Cr}^{3+}\right)$-Polyethyleneimine (PEI)-polymer gel sealant, J. Pet. Sci. Eng. 165, 1, 105-113. doi: 10.1016/j. petrol.2018.01.082.

Jia H., Pu W., Zhao J., Jin F. (2010) Research on the gelation performance of low toxic PEI crosslinking PHPA gel systems as water shutoff agents in low temperature reservoirs, Ind. Eng. Chem. Res. 49, 20, 9618-9624. doi: 10.1021/ie100888q.

Jia H., Zhao J., Jin F., Pu W., Li Y., Li K., Li J. (2012) New insights into the gelation behavior of polyethyleneimine crosslinking partially hydrolyzed polyacrylamide gels, Ind. Eng. Chem. Res. 51, 38, 12155-12166. doi: 10.1021/ie301818f.

Johnson S., Trejo J., Veisi M., Willhite G.P., Liang J., Berkland C. (2010) Effects of divalent cations, seawater, and formation brine on positively charged polyethylenimine/ dextran sulfate/chromium (III) polyelectrolyte complexes and partially hydrolyzed polyacrylamide/chromium (III) gelation, J. Appl. Polym. Sci. 115, 2, 1008-1014. doi: 10.1002/app. 31052 .

Kedir A.S., Seland J.G., Skauge A., Skauge T. (2014) Nanoparticles for enhanced oil recovery: Influence of $\mathrm{pH}$ on aluminumcross-linked partially hydrolyzed polyacrylamide-investigation by rheology and NMR, Energy Fuels 28, 4, 2343-2351. doi: 10.1021/ef402376q.

Koohi A.D., Seftie M.V., Ghalam A.Z., Moghadam A.M., Sabet S.Z. (2010) Rheological characteristics of sulphonated polyacrylamide/chromium triacetate hydrogels designed for water shut-off, Iran. Polym. J. 19, 10, 757-770.

Lakatos I., Lakatos-Szabó J. (2008) Global oil demand and role of chemical EOR methods in the 21st century, Int. J. Oil Gas Coal Technol. 1, 2, 46-64. doi: 10.1504/IJOGCT.2008.016731.
Lashari Z.A., Yang H., Zhu Z., Tang X., Cao C., Iqbal M.W., Kang W. (2018) Experimental research of high strength thermally stable organic composite polymer gel, J. Mol. Liq. 263, 1, 118-124. doi: 10.1016/j.molliq.2018.04.146.

Lenji M.A., Haghshenasfard M., Sefti M.V., Salehi M.B., Heidari A. (2018) Experimental study of swelling and rheological behavior of preformed particle gel used in water shutoff treatment, J. Pet. Sci. Eng. 169, 739-747. doi: 10.1016/j. petrol.2018.06.029.

Liu Y., Bai B., Wang Y. (2010) Applied technologies and prospects of conformance control treatments in China, Oil Gas Sci. Technol. - Rev. IFP Energies nouvelles 65, 6, 859-878. doi: $10.2516 /$ ogst $/ 2009057$.

Liu Y., Dai C., Wang K., Zhao M., Zhao G., Yang S., Yan Z., You Q. (2016) New insights into the hydroquinone (HQ)hexamethylenetetramine (HMTA) gel system for water shuttoff treatment in high temperature reservoirs, J. Ind. Eng. Chem. 35, 1, 20-28. doi: 10.1016/j.jiec.2015.09.032.

Ma Q., Shuler P.J., Aften C.W., Tang Y. (2015) Theoretical studies of hydrolysis and stability of polyacrylamide polymers, Polym. Degrad. Stabil. 121, 1, 69-77. doi: 10.1016/j. polymdegradstab.2015.08.012.

Ma L., Wang S., Long Y., Zhu C., Yang H., Yang T., Liu X., Li X., Bai B., Kang W. (2017) Novel environmentally benign hydrogel: Nano-silica hybrid hydrolyzed polyacrylamide/ polyethyleneimine gel system for conformance improvement in high temperature high salinity reservoir, Society of Petroleum Engineers, Abu Dhabi. doi: 10.2118/188654-MS.

Manrique E.J., Garmeh G., Izadi M., Salehi M., Romero J.L., Aye N.M., Thomas C., Shevelev P. (2012) In-depth sweep efficiency improvement: Screening criteria and engineering approach for pattern evaluation and potential field implementation, Society of Petroleum Engineers, Moscow. doi: 10.2118/160749-RU.

Moghagam A.M., Sefti M.V., Salehi M.B., Naderi H. (2014) Bulk and rheological properties of polyacrylamide hydrogels for water shutoff treatment, Korean J. Chem. Eng. 31, 3, 532-539. doi: 10.1007/s11814-013-0242-1.

Moradi-Araghi A. (1993) Gelation of acrylamide-containing polymers with aminobenzoic acid compounds and water dispersible aldehydes. US5179136A, 10 set. 1990, 12 jan. 1993.

Moradi-Araghi A. (2000) A review of thermally stable gels for fluid diversion in petroleum production, J. Pet. Sci. Eng. 26, 1-4, 1-10. doi: 10.1016/S0920-4105(00)00015-2.

Moradi-Araghi A., Beardmore D.H., Stahl G.A. (1988) The application of gels in enhanced oil recovery: Theory, polymers and crosslinker systems, Water-Soluble Polym. Petrol. Recovery 1, 1, 299-312.

Mumallah N., Shioyama T. (1987) Permeability contrast correction employing a sulfate-free propionate-sequestered chromium (III) solution. US4644073A, 11 mar. 1985, 17 fev. 1987.

Needham R.B., Threlkeld C.B., Gall J.W. (1974) Control of water mobility using polymers and multivalent cations, Society of Petroleum Engineers, Tulsa, OK.

Powell P., Singleton M., Sorbie K. (2004) Combined scale inhibitor and water control treatment. US20040154799A1, 06 fev. 2003, 12 ago. 2004.

Reichenbach-Klinke R., Langlotz B., Wenzke B., Spindler C., Brodt G. (2011) Associative copolymer with favorable properties for the application in polymer flooding, Society of Petroleum Engineers, The Woodlands, TX. doi: 10.2118/141107-MS.

Romero-Zerón L.B., Hum F.M., Kantzas A. (2008) Characterization of crosslinked gel kinects and gel strength by use of NMR, SPE Reserv. Evalu. Eng. 11, 3, 439-453. doi: 10.2118/86548-PA. 
Routson W., Caldwell A. (1972) Method and composition on for controlling flow through subterranean formations. US3701384A, 11 mar. 1971, 31 out. 1972.

Sengupta B., Sharma V.P., Udayabhanu G. (2012) Gelation studies of an organically cross-linked polyacrylamide water shut-off gel system at different temperatures and $\mathrm{pH}$, J. Pet. Sci. Eng. 81, 1, 145-150. doi: 10.1016/j.petrol.2011.12.016.

Sengupta B., Sharma V.P., Udayabhanu G. (2014) In-situ gelation studies of an eco-friendly cross-linked polymer system for water shut-off at high temperatures, Energy Sources Part A Recovery Utilization Env. Effects 36, 13, 1445-1467. doi: 10.1080/15567036.2011.553661.

Seright R.S. (1991) Impact of dispersion on gel placement for profile control, SPE Reserv. Eng. 6, 3, 343-452. doi: 10.2118/ 20127-PA.

Seright R.S., Liang J., Lindquist W.B., Dunsmuir J.H. (2003) Use of X-ray computed microtomography to understand why gels reduce relative permeability to water more than that to oil, J. Pet. Sci. Eng. 39, 3-4, 217-230. doi: 10.1016/S09204105(03)00064-0.

Sheng J.J. (2010) Modern chemical enhanced oil recovery, Gulf Publishing Company, Houston, TX.

Shibayama M., Tanaka T. (1993) Volume phase transition and related phenomena of polymer gels, in: Dušek K. (ed), Responsive gels: Volume transitions I, Springer, Berlin, pp. 1-62. doi: 10.1007/3-540-56791-7__.

Southwell G.P., Posey S.M. (1994) Applications and results of acrylamide-polymer/chromium (III) carboxylate gels, in: SPE/DOE Improved Oil Recovery Symposium, 17-20 April, Tulsa, OK. SPE 27779-MS. doi: 10.2118/35381-MS.

Stavland A., Jonsbraten H.C. (1996) New insights into aluminium citrate/polyacrylamide gels for fluid control, Society of Petroleum Engineers, Tulsa, OK. doi: 10.2118/35381-MS.

Sun F., Lin M., Dong Z., Zhu D., Wang S.L., Yang J. (2016) Effect of composition of PHPA/chromium (III) acetate gels on delayed gelation time, J. Dispers. Sci. Technol. 37, 6, 753759. doi: 10.1080/01932691.2015.1041034.

Sydansk R.D. (1988) A new conformance-improvement-treatment chromium(III) gel technology, Society of Petroleum Engineers, Tulsa, OK. doi: 10.2118/17329-MS.

Sydansk R.D., Moore P.E. (1992) Gel conformance treatments increase oil production in Wyoming, Oil Gas J. 90, 40-45.

Tessarolli F.G.C., Queirós Y.G.C., Elias Mansur C.R. (2014) Evaluation oh $\mathrm{pH}-$ Sensitive hydrogels to control the permeability anisotropy of oil reservoirs, J. Appl. Polym. Sci. 131, 17, 40665-40676. doi: 10.1002/app.40665.

Tessarolli F.G.C., Souza S.T.S., Gomes A.S., Elias Mansur C.R. (2019) Influence of polymer structure on the gelation kinetics and gel strength of acrylamide-based copolymers, bentonite and polyethylenimine systems for conformance control of oil reservoirs, $J$. Appl. Polym. Sci. 136, 22, 47556-47569. doi: 10.1002/app.47556.

Thomas A., Gaillard N., Favero C. (2012) Some key features to consider when studying acrylamide-based polymers for chemical enhanced oil recovery, Oil Gas Sci. Technol. - Rev. IFP Energies nouvelles 67, 6, 887-902. doi: 10.2516/ogst/2012065.

Tongwa P., Baojun B. (2015) A more superior preformed particle gel with potential application for conformance control in mature oilfields, J. Petrol. Explor. Prod. Technol. 5, 2, 201-210. doi: 10.1007/s13202-014-0136-8.

Tongwa P., Nygaard R., Bai B. (2012) Evaluation of a nanocomposite hydrogel for water shut-off in enhanced oil recovery applications: Design, synthesis, and characterization, J. Appl. Polym. Sci. 128, 1, 787-794. doi: 10.1002/app.38258.
Vargas-Vasquez S.M., Romero-Zerón L.B. (2008) A review of the partly hydrolyzed polyacrylamide $\mathrm{Cr}$ (III) acetate polymer gels, J. Pet. Sci. Technol. 26, 4, 481-498. doi: 10.1080/ 10916460701204594.

Wever D.A.Z., Picchioni F., Broekhuis A.A. (2011) Polymers for enhanced oil recovery: A paradigm for structure-property relationship in aqueous solution, Prog. Polym. Sci. 36, 11, 1558-1628. doi: 10.1016/j.progpolymsci.2011.05.006.

Yadav U.S., Mahto V. (2013a) Modeling of partially hydrolyzed polyacrylamide-hexamine-hydroquinone gel system used for profile modification jobs in the oil field, J. Pet. Eng. 2, 1, 1-11. doi: $10.1155 / 2013 / 709248$.

Yadav U.S., Mahto V. (2013b) Rheological study of partially hydrolyzed polyacrylamide-hexamine-pyrocatechol gel system, Int. J. Ind. Chem. 4, 1, 1-8. doi: 10.1186/2228-5547-4-8.

Yadav U.S., Mahto V. (2013c) Investigating the effect of several parameters on the gelation behavior of partially hydrolyzed polyacrylamide-hexamine-hydroquinone gels, Ind. Eng. Chem. Res. 52, 28, 9532-9537. doi: 10.1021/ie400488a.

Yavari-Gohar M.R., Kabiri K., Zohuriaan-Mehr M.J., Hashemi S.A. (2010) Thermo-hydrolytic stability of swelling capacity of superabsorbing composite hydrogels based on AMPS and acrylamide, J. Polym. Res. 17, 2, 151-159. doi: 10.1007/ s10965-009-9301-z.

Zhang L., Pu C., Sang H., Zhao Q. (2015a) Mechanism study of the crosslinking reaction of hydrolyzed polyacrylamide $/ \mathrm{Ac}_{3} \mathrm{Cr}$ in formation water, Energy Fuels 29, 8, 4701-4710. doi: 10.1021/acs.energyfuels.5b00149.

Zhang G., Chen L., Ge J., Jiang P., Zhu X. (2015b) Experimental research of syneresis mechanism of PHPA $/ \mathrm{Cr}^{3+}$ gel, Colloids Surf. A Physicochem. Eng. Aspects 483, 1, 96-103. doi: 10.1016/j.colsurfa.2015.07.048.

Zhang L., Jing C., Liu J., Nasir K. (2017) A study on a copolymer gelant with high temperature resistance for conformance control, J. Energy Res. Technol. 140, 3, 3290732914. doi: 10.1115/1.4038196.

Zhao J., Jia H., Pu W., Liao R. (2011) Influences of fracture aperture on the water-shutoff performance of polyethyleneimine crosslinking partially hydrolyzed polyacrylamide gels in hydraulic fractured reservoirs, Energy Fuels 25, 6, 2616-2624. doi: $10.1021 / \mathrm{ef} 200461 \mathrm{~m}$.

Zhu D., Hou J., Wei Q., Chen Y., Peng K. (2017a) Development of a high-temperature resistant polymer gel system for conformance control in Jidong oilfield, Society of Petroleum Engineers, Indonesia. doi: 10.2118/186235-MS.

Zhu D., Bai B., Hou J. (2017b) Polymer gel systems for water management in high-temperature petroleum reservoirs: A chemical review, Energy Fuels 31. 12, 13063-13087. doi: 10.1021/acs.energyfuels.7b02897.

Zhu D., Hou J., Wei Q., Wu X., Bai B. (2017c) Terpolymer gel system formed by resorcinol-hexamethylenetetramine for water management in extremely high-temperature reservoirs, Energy Fuels 31, 2, 1519-1528. doi: 10.1021/acs.energyfuels. $6 \mathrm{~b} 03188$.

Zhu D., Hou J., Chen Y., Zhao S., Bai B. (2018) In-situ surface decorated polymer microsphere technology for enhanced oil recovery in high-temperature petroleum reservoirs, Energy Fuels 32, 3, 3312-3321. doi: 10.1021/acs.energyfuels.8b00001.

Zhu D., Hou J., Chen Y., Wei Q., Zhao S., Bai B. (2019) Evaluation of terpolymer-gel systems crosslinked by polyethylenimine for conformance improvement in high-temperature reservoirs, Society of Petroleum Engineers 24, 4, 1-15. doi: 10.2118/ 194004-PA. 